\title{
Are Patients with Cardiovascular Disease at Higher Risk for Postoperative Complications following Total Hip or Total Knee Replacements? A Retrospective Cohort Study
}

\author{
Mark Orland ( $\sim$ morlan5@uic.edu ) \\ Nandini Rajaram Siva \\ University of Illinois at Chicago College of Medicine \\ Diego Barragan \\ University of Illinois at Chicago College of Medicine \\ Anshum Sood \\ University of Illinois at Chicago College of Medicine \\ Mark H Gonzalez \\ University of Illinois at Chicago College of Medicine
}

University of Illinois at Chicago College of Medicine https://orcid.org/0000-0002-1842-6187

\section{Research}

Keywords: Cardiovascular Disease, Preoperative Evaluation, Perioperative Care, Clinical Monitoring, Total Hip Replacement, Total Knee Replacement, Big Data Analysis

Posted Date: October 11th, 2021

DOI: https://doi.org/10.21203/rs.3.rs-948339/v1

License: (c) (i) This work is licensed under a Creative Commons Attribution 4.0 International License.

Read Full License 


\section{Abstract}

Background: Cardiovascular disease affects 121.5 million Americans, or $48 \%$ of the adult US population and is the leading cause of death in the United States. The demand for total joint replacement is expected to increase due to an aging population and advances in technology. Given the prevalence of cardiovascular disease and the expected increase in total joint replacement procedures, we sought to examine whether cardiovascular disease was associated with increased postoperative complications in patients undergoing total hip and knee replacements.

\section{Methods:}

CPT codes were used to investigate the American College of Surgeons National Surgical Quality Improvement Program (ACS-NSQIP) database for patients who underwent total hip or knee replacements from 2010 to 2017. Patients were classified as having cardiovascular disease as per the American Health Association guidelines. Patient samples with all possible covariates were included in a multivariate logistic regression analysis. A patient sample size of 119,076 for total hip and 189,297 for total knee replacement was analyzed.

Results: Patients with cardiovascular disease were found to have a statistically significant increased risk for the following postoperative complications: sepsis, wound complications, pneumonia, urinary tract infection, myocardial infarction, unplanned intubation, and cardiac arrest.

Conclusions: Patients with cardiovascular disease undergoing a total hip or knee replacement have increased risk for wound, infectious and cardiovascular-associated postoperative complications. This finding necessitates the need for more frequent and sooner postoperative visits, a stringent cardiovascular preoperative evaluation, and patient education on the increased postoperative risks of joint replacements to lower the incidence of complications.

\section{Introduction}

Currently more than 7 million Americans live with a hip or knee replacement (1). The prevalence of total hip arthroplasty (THA) and total knee arthroplasty (TKA) is expected to increase. Prediction models estimate that the number of THA and TKA in the United States will increase by $85 \%$ and $71 \%$ respectively, by the year 2050 (2). The decreasing mean age at which patients are undergoing total joint replacements can partially explain this rise in volume. Additionally a recent report from the CDC indicates that the number of hip replacements from 2000 to 2010 more than tripled in adults aged from 45 to 54 (3). Given this trend, it is important to practice judicious patient selection with preoperative optimization and standardization for total joint replacements to minimize patient complications and hospital costs.

While the number of total joint replacements increases, cardiovascular disease continues to be the leading cause of death in both men and women in the United States (4). The American Heart Association 
(AHA) reports that cardiovascular disease affects 121.5 million Americans, or $48 \%$ of the adult US population (5).

Although cardiovascular disease has been extensively studied as a prognostic indicator for surgical outcomes, previous studies have not assessed its prevalence and corresponding complications following total joint replacement (6-11). Moreover, total blood loss in surgery is generally associated with postoperative complications, and THA and TKA are known to have some of the highest with an estimated average of $1500 \mathrm{~mL}$ and $1472 \mathrm{~mL}$ of blood respectively $(12,13)$. Therefore, we sought to examine whether patients with cardiovascular disease undergoing total joint replacement were more at risk for major postoperative complications when compared to those without cardiovascular disease.

\section{Materials And Methods Data Collection}

This was a retrospective analysis of data collected from the American College of Surgery National Quality Improvement Database (ACS-NSQIP), a national database of clinical information collected from over 500 participating hospitals across the United States (14).

Based on the data in the ACS-NSQIP, patients undergoing THA or TKA from 2010 to 2017 were identified. Current Procedural Terminology (CPT) codes were used to identify both surgeries, specifically 27130 for THA and 27447 for TKA $(15,16)$. To account for potential confounding variable in subsequent analyses, data were filtered to only include samples that accounted for the following variables: sex, race, smoking status, abnormal renal function (as indicated by dialysis use), thrombocytopenia (platelet count < 150,000 cells $/ \mathrm{mm}^{3}$ ), anemia (hematocrit level $<36 \%$ for women and $<39 \%$ for men per the World Health Organization), age, obesity (body mass index $>30 \mathrm{~kg} / \mathrm{m}^{2}$ ), diabetic history, COPD history, bleeding disorder, steroid or immunosuppressant use, dyspnea present at rest, and preoperative blood transfusions within 72 hours of the procedure (17).

\section{Data Stratification}

Based on criteria from the World Health Organization, preoperative cardiovascular disease was defined as a patient with a history of coronary artery disease, cerebrovascular disease, peripheral artery disease, rheumatic and congenital heart disease, and history of venous thromboembolisms (18). Patients with documented history of ischemic heart disease from atherosclerosis, history of prior myocardial infarctions, congestive heart failure, prior venous thromboembolisms, and congenital heart disease were stratified as those with existing cardiovascular disease pre-operatively. Cardiovascular disease in the TKA and THA cohorts were analyzed with respect to postoperative complications that occurred within thirty days of the surgery.

\section{Thirty-Day Postoperative Complications}


The postoperative variables analyzed consisted of wound complications which included periprosthetic complications (wound infection, surgical site infection, organ space infection, and wound dehiscence), clotting complications (deep vein thrombosis, pulmonary embolism, myocardial infarction, stroke), blood transfusions, unplanned intubations, urinary tract infections (UTIs), and major systemic complications including sepsis and cardiac arrest.

\section{Statistical Analysis}

All analyses were done with the R software, version 3.6.1 (19). Univariate analysis utilizing Pearson's $\chi^{2}$ test was performed to compare patient preoperative clinical data and operative time to determine any confounding variates in both procedures separately. The length of operation and patient age for THA and TKA were separately stratified into four quartiles based on the mean in each, to be analyzed as categorical rather than continuous variables for statistical analysis in the logistic regression. Patient demographics and comorbidities that were significantly associated with cardiovascular disease were included as covariate variables and thus accounted for in the multivariate logistic regression (MLR). MLR analysis was used to test the relationship between pre-operative cardiovascular disease and postoperative complications in each procedure separately. Odds ratios (OR) and $95 \%$ confidence intervals (Cl) were reported. Statistical significance for all analyses was set as $p<0.05$.

\section{Results}

\section{Total Hip Replacement}

The following covariates from the $\chi^{2}$ test were found to be significant for THA via univariate analysis: sex, race, smoking status, abnormal renal function, thrombocytopenia, anemia, age, obesity, diabetes, COPD, bleeding disorders, steroid or immunosuppressant use, dyspnea at rest, and preoperative blood transfusions. The full results can be found in Table 1. 
Table 1

Univariate analysis of all potential preoperative and perioperative covariates in patients undergoing THA.

\section{Preoperative and Perioperative Variables}

Cardiovascular Disease
$(n=68,306)$

Count Percent (\%)
No Disease

$(n=50,730)$

Count Percent

(\%) value

Operative Time

1st Quartile

2nd Quartile

3rd Quartile

4th Quartile

Sex

Female

Male

Race

American Indian or Alaska Native 264

17,572

16,682

17,062

16,990

24.9

25.7

24.4

25.0

53.5

46.5

31,785

59,461

0.4

87.1

227

0.3

Native Hawaiian or Pacific

Islander

Asian

1,093

1.6

799

1.6

Black or African American

7,261

10.6

3,153

6.2

Smoking Status

8,407

12.3

0.3

198

3,401

5.0

17.2

11,778

Age

0-58

59-65

66-72

$73+$

Obesity

11

40

\begin{tabular}{ll}
\hline 293 & 0.6 \\
\hline 46,381 & 91.4 \\
\hline 144 & 0.3 \\
\hline
\end{tabular}

$<0.001$

0.17

$<0.001$

$28,882 \quad 56.9$

$21,888 \quad 43.1$ 


\begin{tabular}{|lllllr|}
\hline $\begin{array}{l}\text { Preoperative and Perioperative } \\
\text { Variables }\end{array}$ & \multicolumn{2}{l}{$\begin{array}{l}\text { Cardiovascular Disease } \\
(\mathbf{n = 6 8 , 3 0 6 )}\end{array}$} & \multicolumn{2}{l}{$\begin{array}{l}\text { No Disease } \\
(\mathbf{n = 5 0 , 7 3 0 )}\end{array}$} & \multirow{2}{*}{$\begin{array}{l}\text { p- } \\
\text { value }\end{array}$} \\
\cline { 2 - 5 } & Count & Percent (\%) & Count & $\begin{array}{l}\text { Percent } \\
(\%)\end{array}$ & \\
\hline Diabetes & 12,370 & 18.1 & 2,015 & 4.0 & $<0.001$ \\
\hline COPD & 3,470 & 5.1 & 1,290 & 2.5 & $<0.001$ \\
\hline Bleeding Disorder & 2,016 & 3.0 & 639 & 1.3 & $<0.001$ \\
\hline $\begin{array}{l}\text { Steroid or Immunosuppressant } \\
\text { Use }\end{array}$ & 2,756 & 4.0 & 1,678 & 3.3 & $<0.001$ \\
\hline Dyspnea at Rest & 4,042 & 5.9 & 1,273 & 2.5 & $<0.001$ \\
\hline Preoperative Transfusion & 94 & 0.1 & 44 & 0.1 & 0.01 \\
\hline
\end{tabular}

119,076 patients had data recorded for all of the above covariates. $68,306(57.4 \%)$ had a history of cardiovascular disease, while 50,730 (42.6\%) did not. The results of the MLR analysis examining the association between cardiovascular disease and postoperative complications while accounting for all covariates can be found in Table 2. There was a statistically significantly increased incidence of the following complications in patients with cardiovascular disease: sepsis, postoperative transfusions, wound complications (surgical site infections, deep wound infection, organ space infection, wound dehiscence, and wound infection), pneumonia, urinary tract infections (UTIs), myocardial infarction, unplanned intubation, stroke, deep vein thrombosis (DVT), and cardiac arrest $(p<0.05, O R>1)$. Full results can be found in Table 2 . 
Table 2

MLR analysis of postoperative complications in patients with cardiovascular disease undergoing THA compared to those without.

\begin{tabular}{|llll|}
\hline Postoperative Complications & Odds Ratio & $95 \%$ Cl & p-value \\
\hline Sepsis & 2.64 & $1.44-4.85$ & 0.002 \\
\hline Surgical Site Infection & 1.44 & $1.22-1.71$ & $<0.001$ \\
\hline Deep Wound Infection & 1.69 & $1.3-2.2$ & $<0.001$ \\
\hline Organ Space Infection & 1.83 & $1.41-2.38$ & $<0.001$ \\
\hline Wound Dehiscence & 1.52 & $1.06-2.19$ & 0.02 \\
\hline Wound Infection & 1.62 & $1.44-1.83$ & $<0.001$ \\
\hline Pneumonia & 1.62 & $1.29-2.03$ & $<0.001$ \\
\hline Urinary Tract Infection & 1.56 & $1.36-1.79$ & $<0.001$ \\
\hline Myocardial Infarction & 3.35 & $2.39-4.7$ & $<0.001$ \\
\hline Unplanned Intubation & 2.34 & $1.65-3.32$ & $<0.001$ \\
\hline Postoperative Stroke & 1.87 & $1.21-2.87$ & 0.005 \\
\hline Postoperative Transfusion & 1.16 & $1.1-1.21$ & $<0.001$ \\
\hline Deep Vein Thrombosis & 1.37 & $1.13-1.67$ & 0.001 \\
\hline Cardiac Arrest & 2.28 & $1.32-3.93$ & 0.003 \\
\hline Pulmonary Embolism & 0.88 & $0.7-1.12$ & 0.29 \\
\hline
\end{tabular}

\section{Total Knee Replacement}

Univariate analysis of the preoperative and perioperative variables of patients undergoing TKA showed the same covariates as THA. The full results can be found in Table 3 . 
Table 3

Univariate analysis of all potential demographic and preoperative covariates in patients undergoing TKA.

\section{Preoperative and Perioperative Variables}

Cardiovascular Disease $(n=126,086)$
No Disease

$(n=63,211)$ pvalue

\section{Count $\quad$ Percent (\%) $\quad$ Count Percent}

(\%)

Operative Time

1st Quartile

33,286

26.4

30,197

23.9

31,101

24.7

31,502

25.0

$15,509 \quad 24.5$

4th Quartile

Sex

Female

77,423

48,663

61.4

38.6

22,849

$<0.001$

Race

American Indian or Alaska Native

730

0.6

444

0.7

White

108,229

85.8

$57,542 \quad 91.0$

Native Hawaiian or Pacific Islander

577

0.5

268

0.4

Asian

3,298

2.6

1,358

2.1

Black or African American

13,252

10.5

3,599

5.7

Smoking Status

9,929

7.9

6,201

9.8

$<0.001$

Abnormal Renal Function

197

0.2

99

0.2

$<0.001$

Thrombocytopenia

6,432

5.1

2,448

3.9

$<0.001$

Anemia

18,850

15.0

5,488

8.7

$<0.001$

Age

$0-58$

59-65

66-72

$73+$

Obesity

19,491

29,721

36,787

40,087

86,013
15.5

23.6

29.2

31.8

68.2

$<0.001$

$18,011 \quad 28.5$

$17,130 \quad 27.1$

$15,424 \quad 24.4$

$12,646 \quad 20.0$

$34,505 \quad 54.6$

$<0.001$ 


\begin{tabular}{|llllll|}
\hline $\begin{array}{l}\text { Preoperative and Perioperative } \\
\text { Variables }\end{array}$ & \multicolumn{2}{l}{$\begin{array}{l}\text { Cardiovascular Disease } \\
(\mathbf{n = 1 2 6 , 0 8 6 )}\end{array}$} & \multicolumn{2}{l|}{$\begin{array}{l}\text { No Disease } \\
(\mathbf{n = 6 3 , 2 1 1})\end{array}$} & \multicolumn{2}{c|}{$\begin{array}{c}\text { p- } \\
\text { value }\end{array}$} \\
\cline { 2 - 5 } & Count & Percent (\%) & Count & $\begin{array}{l}\text { Percent } \\
(\%)\end{array}$ & \\
\hline Diabetes & 30,013 & 23.8 & 4,295 & 6.8 & $<0.001$ \\
\hline COPD & 5,349 & 4.2 & 1,540 & 2.4 & $<0.001$ \\
\hline Bleeding Disorder & 3,473 & 2.8 & 891 & 1.4 & $<0.001$ \\
\hline $\begin{array}{l}\text { Steroid or Immunosuppressant } \\
\text { Use }\end{array}$ & 4,554 & 3.6 & 2,240 & 3.5 & 0.46 \\
\hline Dyspnea at Rest & 8,437 & 6.7 & 2,060 & 3.3 & $<0.001$ \\
\hline Preoperative Transfusion & 45 & 0.0 & 19 & 0.0 & 0.62 \\
\hline
\end{tabular}

189,297 patients had data recorded for all covariates. 126,086 (66.6\%) had a history of cardiovascular disease, while 63,211 (33.4\%) did not. The results of the MLR analysis can be found in Table 4. The following postoperative complications demonstrated an increased incidence in patients with a cardiovascular disease: sepsis, postoperative transfusions, wound complications (surgical site infections, deep surgical infection, wound dehiscence, and wound infection), pneumonia, UTIs, myocardial infarction, unplanned intubation, stroke, and cardiac arrest $(p<0.05,0 R>1)$. 
Table 4

Multivariate analysis of all postoperative complications in patients with cardiovascular disease undergoing TKA compared to those without.

\begin{tabular}{|llll|}
\hline Postoperative Complications & Odds Ratio & $95 \%$ Cl & p-value \\
\hline Sepsis & 2.80 & $1.59-4.94$ & $<0.001$ \\
\hline Surgical Site Infection & 1.25 & $1.07-1.46$ & 0.005 \\
\hline Deep Wound Infection & 1.58 & $1.14-2.18$ & 0.006 \\
\hline Organ Space Infection & 1.29 & $1-1.66$ & 0.047 \\
\hline Wound Dehiscence & 1.61 & $1.26-2.05$ & $<0.001$ \\
\hline Wound Infection & 1.34 & $1.2-1.5$ & $<0.001$ \\
\hline Pneumonia & 1.55 & $1.29-1.88$ & $<0.001$ \\
\hline Urinary Tract Infection & 1.39 & $1.24-1.56$ & $<0.001$ \\
\hline Myocardial Infarction & 2.73 & $2.03-3.67$ & $<0.001$ \\
\hline Unplanned Intubation & 2.14 & $1.56-2.94$ & $<0.001$ \\
\hline Postoperative Stroke & 1.87 & $1.26-2.76$ & 0.002 \\
\hline Postoperative Transfusion & 1.27 & $1.21-1.34$ & $<0.001$ \\
\hline Deep Vein Thrombosis & 0.92 & $0.82-1.02$ & 0.12 \\
\hline Cardiac Arrest & 2.03 & $1.32-3.14$ & 0.001 \\
\hline Pulmonary Embolism & 1.01 & $0.88-1.16$ & 0.86 \\
\hline
\end{tabular}

\section{Discussion}

Although it is generally accepted by clinicians that cardiovascular disease is associated with certain postoperative complications, specifics regarding which complications following total joint replacements has not been examined. Our results showed that cardiovascular disease is associated with a higher risk of every potential post-operative complication documented barring venous thromboembolisms in the thirty-day period following THA or TKA. These complications were not limited to those typically associated with, and accounted for, in pre-operative cardiac risk indices such as postoperative cardiac arrest, myocardial infarctions or strokes, but also included wound care complications, systemic infections and several other complications. Reasons for this may include the association of delayed wound healing with cardiovascular disease, potentially due to its complex impact on the hemostatic and remodeling stage of healing $(20,21)$. While the delay in wound healing itself can lead to a nidus for infection in the post-operative immunocompromised state, cardiovascular disease and its impact on the immune system is still being explored as a potential immunosuppressed state $(22,23)$. Findings such as these point to 
the necessity of further research examining the pathway of healing and infection and how cardiovascular disease can impact. Prior to further advancements in optimal wound care and cardioimmunology, patients with cardiovascular disease and planned total joint replacements

should have more frequent postoperative follow-ups with their surgical care team, be flagged preoperatively for increased medical clearance and optimization prior to surgery and be well-informed of the increased risk of complications postoperatively.

Bohl et. al found that the median day of diagnosis of UTIs and surgical site infections following total joint replacements occurred on postoperative day 8 and 17, respectively (24). However, given that followups after surgery for wound care are recommended to be by 2 weeks, surgical infections may go undiagnosed for longer if the follow-up is at 14 days progressing to more serious infections and potential sepsis $(25,26)$. Due to the significantly higher rate of infection in those with cardiovascular disease, the patient's care team should educate the patient on the need for frequent and sooner postoperative visits to with the surgical care team to minimize this chance, as well as have a lower threshold for follow-up if infectious symptoms arise. These frequent follow-ups can also tailor antithrombotic management for patients undergoing total joint replacements to minimize the risk of post-operative myocardial infarctions and strokes, as well as the risk of bleeding.

To minimize the complications associated with cardiovascular disease, we recommend a thorough preoperative evaluation of cardiovascular disease during the preoperative medical clearance process including collaboration with patients' primary care team. This planning can help improve patient outcomes, reduce length of hospital stay, and lower the cost of care $(27,28)$. Currently, orthopaedic surgeries are considered intermediate risk for cardiac death or nonfatal myocardial infarctions postoperatively which does not necessitate stress testing, echocardiograms, or cardiology consults in patients with cardiovascular disease (29). However, as patients with cardiovascular disease are suffering more postoperative strokes and myocardial infarctions after total joint replacements, the benefit of treating these as a higher risk surgeries with more stringent preoperative evaluations should be examined in future research.

When preoperative screening identifies patients with cardiovascular disease, shared decision making between the patient and the care team can help the patient understand and balance the risks and benefits of the surgery and postoperative care. It also gives the team more opportunity to stress the importance of mitigating modifiable risk factors contributing to cardiovascular disease including uncontrolled hypertension, diabetes, smoking, diet, and physical activity (30-32). In addition to patients' primary care team being aware of a patient's choice for an elective joint replacement, orthopaedic surgeons must be aware of the importance of working closely with the patient and rest of the care team to optimize patients' cardiovascular health prior to surgery.

The main limitations of this study result from the multicentered nature of the database. We cannot measure how surgical experience may have acted as a confounder, are limited to analyzing only the variables in the dataset as potential confounders, and cannot comment on if patients with cardiovascular 
disease received any form of pre-operative optimization or not. Additionally, our study found that patients with cardiovascular disease undergoing TKA were not at higher risk for deep vein thrombosis (DVT) despite the literature suggesting an association between TKA and DVTs (33-36). Potential reasons for this include residual effects of aspirin or an underpowered analysis due to the low incidence of DVTs following total knee replacements.

\section{Conclusions}

Patients with cardiovascular disease undergoing a total hip or knee replacement have increased risk for wound, infectious and cardiovascular-associated postoperative complications. This finding necessitates the need for more frequent and sooner postoperative visits, a stringent cardiovascular preoperative evaluation, and patient education on the increased postoperative risks of joint replacements to lower the incidence of complications.

\section{Declarations}

Ethics Approval and Consent to Participate: Not applicable.

Consent for Publication: Not applicable.

Availability of Data and Materials: The datasets analyzed during the current study are available in the American College of Surgeons National Surgical Quality Improvement Program repository, available by request: https://www.facs.org/quality-programs/acs-nsqip/participant-use

Competing Interests: The authors declare that they have no competing interests.

Funding: The authors received no financial support for the research, authorship, and/or publication of this article.

Authors' Contributions: MO formulated the idea for the paper and wrote the majority. NR helped write the paper and edit it. DB performed that data analysis. AS edited the paper. AH helped compile the data for subsequent analysis. MG is the principal investigator of the lab.

Acknowledgements: Not applicable

\section{References}

1. Sloan M, Premkumar A, Sheth NP. Projected volume of primary total joint arthroplasty in the u.s., 2014 to 2030. J Bone Jt Surg - Am Vol. 2018;100(17):1455-60.

2. Kremers HM, Larson DR, Crowson CS, Kremers WK, Washington RE, Steiner CA, et al. Prevalence of total hip and knee replacement in the United States. J Bone Jt Surg - Am Vol. 2014;97(17):1386-97. 
3. Wolford ML, Palso K, Bercovitz A. Hospitalization for total hip replacement among inpatients aged 45 and over: United States, 2000-2010. NCHS data brief. 2015.

4. Products - Data. Briefs - Number 355 - January 2020.

5. Benjamin EJ, Muntner P, Alonso A, Bittencourt MS, Callaway CW, Carson AP, et al. Heart Disease and Stroke Statistics-2019 Update: A Report From the American Heart Association. Vol. 139, Circulation. 2019. 56-528 p.

6. Smilowitz NR, Gupta N, Guo Y, Beckman JA, Bangalore S, Berger JS. Trends in cardiovascular risk factor and disease prevalence in patients undergoing non-cardiac surgery. Heart. 2018;104(14):1180-6.

7. Hammill BG, Curtis LH, Bennett-Guerrero E, O'Connor CM, Jollis JG, Schulman KA, et al. Impact of heart failure on patients undergoing major noncardiac surgery. Anesthesiology. 2008;108(4):559-67.

8. Huang BZ, Camp MS. Burden of preoperative cardiovascular disease risk factors on breast cancer surgery outcomes. J Surg Oncol. 2016;114(2):144-9.

9. Hernandez AF, Whellan DJ, Stroud S, Sun JL, O'Connor CM, Jollis JG. Outcomes in heart failure patients after major noncardiac surgery. J Am Coll Cardiol. 2004;44(7):1446-53.

10. Fayad A, Ansari MT, Yang H, Ruddy T, Wells GA. Perioperative Diastolic Dysfunction in Patients Undergoing Noncardiac Surgery Is an Independent Risk Factor for Cardiovascular Events: A Systematic Review and Meta-analysis. Anesthesiology. 2016;125(1):72-91.

11. Lee TH, Marcantonio ER, Mangione CM, Thomas EJ, Polanczyk CA, Cook EF, et al. Derivation and prospective validation of a simple index for prediction of cardiac risk of major noncardiac surgery. Circulation. 1999 Sep;100(10):1043-9.

12. Park JH, Kim HS, Yoo JH, Kim JH, Sung KH, Kim JY, et al. Perioperative Blood Loss in Bipolar Hemiarthroplasty for Femoral Neck Fracture: Analysis of Risk Factors. Hip Pelvis [Internet]. 2013 Jun 1 [cited 2021 Mar 18];25(2):110. Available from: https://hipandpelvis.or.kr/DOlx.php? id=10.5371/hp.2013.25.2.110.

13. Sehat KR, Evans R, Newman JH. How much blood is really lost in total knee arthroplasty? Correct blood loss management should take hidden loss into account. In: Knee [Internet]. Knee; 2000 [cited 2021 Mar 18]. p. 151-5. Available from: https://pubmed.ncbi.nlm.nih.gov/10927208/.

14. Hussain AK, Cheung ZB, Vig KS, Phan K, Lima MC, Kim JS, et al. Hypoalbuminemia as an Independent Risk Factor for Perioperative Complications Following Surgical Decompression of Spinal Metastases. Glob Spine J. 2019;9(3):321-30.

15. Hips Systems Coding Reference Guide. Zimmer Biomet. 2019.

16. Knee Systems Coding Reference Guide. Zimmer Biomet. 2019.

17. Organization WH. Nutritional Anaemias. Report of a WHO Scientific Group. 1968.

18. Organization WH. Cardiovascular diseases (CVDs) [Internet]. Cardiovascular diseases. 2021. Available from: https://www.who.int/en/news-room/fact-sheets/detail/cardiovascular-diseases(cvds). 
19. R Core Team. R: A language and environment for statistical computing. [Internet]. Vienna, Austria, $R$ foundation for Statistical Computing, 2019. [cited 2021 Jul 13]. Available from: https://www.rproject.org/.

20. Frykberg RG, Banks J. Challenges in the Treatment of Chronic Wounds. Adv Wound Care [Internet]. 2015 Sep [cited 2021 Jul 13];4(9):560. Available from: / pmc/articles/PMC4528992/.

21. Guo S, DiPietro LA. Factors Affecting Wound Healing. J Dent Res [Internet]. 2010 Mar [cited 2021 Jul 13];89(3):219. Available from: /pmc/articles/PMC2903966/.

22. Swirski FK, Nahrendorf M. Cardioimmunology: the immune system in cardiac homeostasis and disease. Nat Rev Immunol 20181812 [Internet]. 2018 Sep 18 [cited 2021 Jul 13];18(12):733-44. Available from: https://www.nature.com/articles/s41577-018-0065-8.

23. Lin CD, Tona F, Osto E. The crosstalk between the cardiovascular and the immune system. Vasc Biol [Internet]. 2019 Sep 1 [cited 2021 Jul 13];1(1):H83-8. Available from: https://vb.bioscientifica.com/view/journals/vb/1/1/VB-19-0023.xml.

24. Bohl DD, Ondeck NT, Basques BA, Levine BR, Grauer JN. What Is the Timing of General Health Adverse Events That Occur After Total Joint Arthroplasty? Clin Orthop Relat Res. 2017;475(12):2952-9.

25. Total. knee arthroplasty - UpToDate.

26. Total. hip arthroplasty - UpToDate.

27. Oresanya LB, Lyons WL, Finlayson E. Preoperative Assessment of the Older Patient: A Narrative Review. JAMA. 2014 May;311(20):2110-20.

28. Partridge JSL, Harari D, Martin FC, Dhesi JK. The impact of pre-operative comprehensive geriatric assessment on postoperative outcomes in older patients undergoing scheduled surgery: a systematic review. Anaesthesia. 2014 Jan;69(s1):8-16.

29. LA F, KE JABKABHCEC F, et al. ACC/AHA 2007 guidelines on perioperative cardiovascular evaluation and care for noncardiac surgery: a report of the American College of Cardiology/American Heart Association Task Force on Practice Guidelines (Writing Committee to Revise the 2002 Guidelines on Perioperative Cardiovascular Evaluation for Noncardiac Surgery): developed in collaboration with the American Society of Echocardiography, American Society of Nuclear Cardiology, Heart Rhythm Society, Society of Cardiovascular Anesthesiolog. Circulation [Internet]. 2007 Oct [cited $2021 \mathrm{Jul}$ 13];116(17). Available from: https://pubmed.ncbi.nlm.nih.gov/17901357/.

30. Spring B, Moller AC, Colangelo LA, Siddique J, Roehrig M, Daviglus ML, et al. Healthy Lifestyle Change and Subclinical Atherosclerosis in Young Adults. Circulation. 2014;130(1):10-7.

31. Peterson JC, Charlson ME, Wells MT, Altemus M. Depression, coronary artery disease, and physical activity: how much exercise is enough? Clin Ther. 2014 Nov;36(11):1518-30.

32. Hall SL, Lorenc T. Secondary prevention of coronary artery disease. Am Fam Physician. 2010 Feb;81(3):289-96.

33. Sharfman ZT, Campbell JC, Mirocha JM, Spitzer Al. Balancing Thromboprophylaxis and Bleeding in Total Joint Arthroplasty: Impact of Eliminating Enoxaparin and Predonation and Implementing 
Pneumatic Compression and Tranexamic Acid. J Arthroplasty. 2016 Jun;31(6):1307-12.

34. Dua A, Desai SS, Lee CJ, Heller JA. National Trends in Deep Vein Thrombosis following Total Knee and Total Hip Replacement in the United States. Ann Vasc Surg. 2017 Jan;38:310-4.

35. Woon CYL, Shah RR, Pardi BM, Schwartz BE, Goldstein JM, Cipparrone NE, et al. Aspirin Alone Is Not Enough to Prevent Deep Venous Thrombosis After Total Joint Arthroplasty. Orthopedics. 2019 Jan;42(1):48-55.

36. Wilson DGG, Poole WEC, Chauhan SK, Rogers BA. Systematic review of aspirin for thromboprophylaxis in modern elective total hip and knee arthroplasty. Bone Joint J. 2016 Aug;98B(8):1056-61. 